\title{
Therapeutic hypothermia in drowning induced hypoxic brain injury:
} a case report Ramesh K Batra* and Jonathan J Paddle

\author{
Address: Intensive Care Unit, Royal Cornwall Hospital NHS Trust, Truro, UK \\ Email: Ramesh K Batra* - drrkbatra@gmail.com; Jonathan J Paddle - jonathan.paddle@rcht.cornwall.nhs.uk \\ * Corresponding author
}

Published: 27 November 2009

Cases Journal 2009, 2:9103 doi:10.1/186/1757-1626-2-9103

This article is available from: http://www.casesjournal.com/content/2/I/9103

(C) 2009 Batra and Paddle; licensee BioMed Central Ltd.

This is an Open Access article distributed under the terms of the Creative Commons Attribution License (http://creativecommons.org/licenses/by/2.0), which permits unrestricted use, distribution, and reproduction in any medium, provided the original work is properly cited.
Received: 23 September 2009

Accepted: 27 November 2009

\begin{abstract}
Background: Although therapeutic hypothermia for neuroprotection has been in use for over half a century but its use has been controversial in absence of proper guidelines. However for over two decades there has been revived interest in mild therapeutic hypothermia $\left(32-34^{\circ} \mathrm{C}\right)$ for neuroprotection.

Case: A 17 year-old female tourist was rescued from sea. She received cardio-pulmonary resuscitation for about 16 minutes. But she had sustained significant neurological insult as a result of hypoxic brain injury. Therapeutic hypothermia was added to her regime of neuroprotection in intensive care unit, and her neurological status improved in just $\mathbf{8}$ hours with full correction of her coma score by day 4 .
\end{abstract}

\section{Introduction}

Therapeutic hypothermia for neuroprotection in brain injury has been used since the 1950s. Theoretical benefits include reduction in cerebral metabolic demands, reduction in intracranial pressure, and attenuation of an array of temperature dependent deleterious biochemical processes [1]. Therapeutic hypothermia may be neuroprotective in brain injury from a number of causes. In posthypoxic coma following cardiac arrest due to ventricular fibrillation, cooling patients to between $32^{\circ} \mathrm{C}$ and $34^{\circ} \mathrm{C}$ for 12 to 24 hours has been shown to reduce mortality and improve neurological outcome [2,3]. The neurological outcome from traumatic brain injury may also be improved with therapeutic hypothermia [4,5]. Evidence to support the use of hypothermia to manage brain injury in other conditions is weaker, but its beneficial effect has been reported in conditions such as stroke [6] and in a victim of drowning [7].
We describe the management of a patient with hypoxic brain injury post drowning, in-whom controlled therapeutic hypothermia was used.

\section{Case}

A 17 year-old Caucasian female tourist was found floating in the sea after being caught in a strong rip and was pulled out. She was lifeless at the scene with no palpable pulse and bystander cardio-pulmonary resuscitation (CPR) was commenced immediately and continued for the next 10 minutes until the arrival of paramedics. Her Glasgow coma score (GCS) was 3, and her pupils were fixed and dilated. CPR was continued for a further 6 minutes, whilst a total of $2 \mathrm{mg}$ of Epinephrine and $3 \mathrm{mg}$ of Atropine were administered intravenously. This resulted in return of spontaneous circulation though with limited respiratory efforts, and an endotracheal tube was inserted to facilitate ventilation during transfer to hospital. 
On arrival in the emergency department after 10 minutes by helicopter she was in sinus rhythm with heart rate of 84 beats per minute and blood pressure of $120 / 75 \mathrm{mmHg}$. Her neurological status remained unchanged with GCS of 3 and fixed and dilated pupils. Chest $\mathrm{x}$-ray revealed bilateral pulmonary infiltrates. Initial arterial blood gases showed profound metabolic acidosis with temperature corrected $\mathrm{pH}$ of 6.57 (reference range [RR], 7.35 - 7.45), $\mathrm{PCO}_{2}$ of $7.83 \mathrm{kPa}(\mathrm{RR}, 4.5-5.5 \mathrm{kPa}), \mathrm{PO}_{2}$ of $51.9 \mathrm{kPa}$ on $100 \% \mathrm{FiO}_{2}$ and $\mathrm{HCO}_{3}$ of $3.6 \mathrm{mmol} / \mathrm{L}(\mathrm{RR}, 22-26 \mathrm{mmol} /$ $\mathrm{L})$, base excess of $-28.1 \mathrm{mmol} / \mathrm{L}(\mathrm{RR},-2$ to $+2 \mathrm{mmol} / \mathrm{L})$, and lactate of $28 \mathrm{mmol} / \mathrm{L}(\mathrm{RR},<2 \mathrm{mmol} / \mathrm{L})$. Her core temperature on admission was $33.4^{\circ} \mathrm{C}$.

She was transferred to the Intensive care unit with a diagnosis of severe hypoxic brain injury and aspiration pneumonia. Conventional neuro-protective measures were commenced. This included sedation with a Propofol infusion, nursing at $15^{\circ}$ head-up tilt with the patient's head in neutral alignment and controlled mechanical ventilation to maintain an arterial $\mathrm{PaCO}_{2}$ of $4.5-5 \mathrm{kPa}$. Intravenous fluids were administered to maintain a normovolaemic state and nutrition commenced via a naso-gastric tube. She was also commenced on antibiotics for the aspiration pneumonia. We decided to use therapeutic hypothermia to try and ameliorate her hypoxic brain injury. This was achieved by the insertion of the Cool-Guard endovascular cooling catheter, which was sited in her femoral vein.

By the time the catheter had been sited her core temperature had dropped to $30.6^{\circ} \mathrm{C}$, presumably due to redistribution of cold peripheral blood to the core, so the Cool-
Guard was initially used to warm her to the target temperature of $34^{\circ} \mathrm{C}$. Cooling was continued, with a target temperature of $34^{\circ} \mathrm{C}$ for 20 hours (Figure 1). Active cooling was stopped after 20 hours and the patient was allowed to passively re-warm. Overall, her core temperature was an average of $34.2^{\circ} \mathrm{C}$ for the first 24 hours of her admission. Her severe acidaemia corrected over the first 8 hours (Figure 2). Her pupils became responsive to light in 8 hours and reached normal size and reaction in 40 hours. Her GCS improved by day 3 to the point of spontaneous eye opening and obeying commands. On day 2 she suffered a seizure, confirmed by electroencephalography, which was controlled with intravenous Phenytoin $(18 \mathrm{mg} / \mathrm{kg})$. On day 4 she was transferred to a high dependency unit in France where she continued to improve to a GCS of 15 . She was subsequently transferred to a rehabilitation facility. Three months post injury she was independently performing all her daily activities with no neurological deficit and the last follow-up confirmed that her discharge home was expected.

\section{Discussion}

Therapeutic hypothermia for the specific indication of hypoxic brain injury post cardiac arrest has not been subject to a formal randomized controlled trial, and we cannot plausibly prove that hypothermia contributed to the good outcome in this case. However, clinical trials of the use of therapeutic hypothermia for other forms of brain injury, particularly brain injury post cardiac arrest $[2,3]$, where the mechanism of neurological damage is likely to be similar, suggest that this treatment may have a role. Schaller and Graf [8] reviewed several experimental and

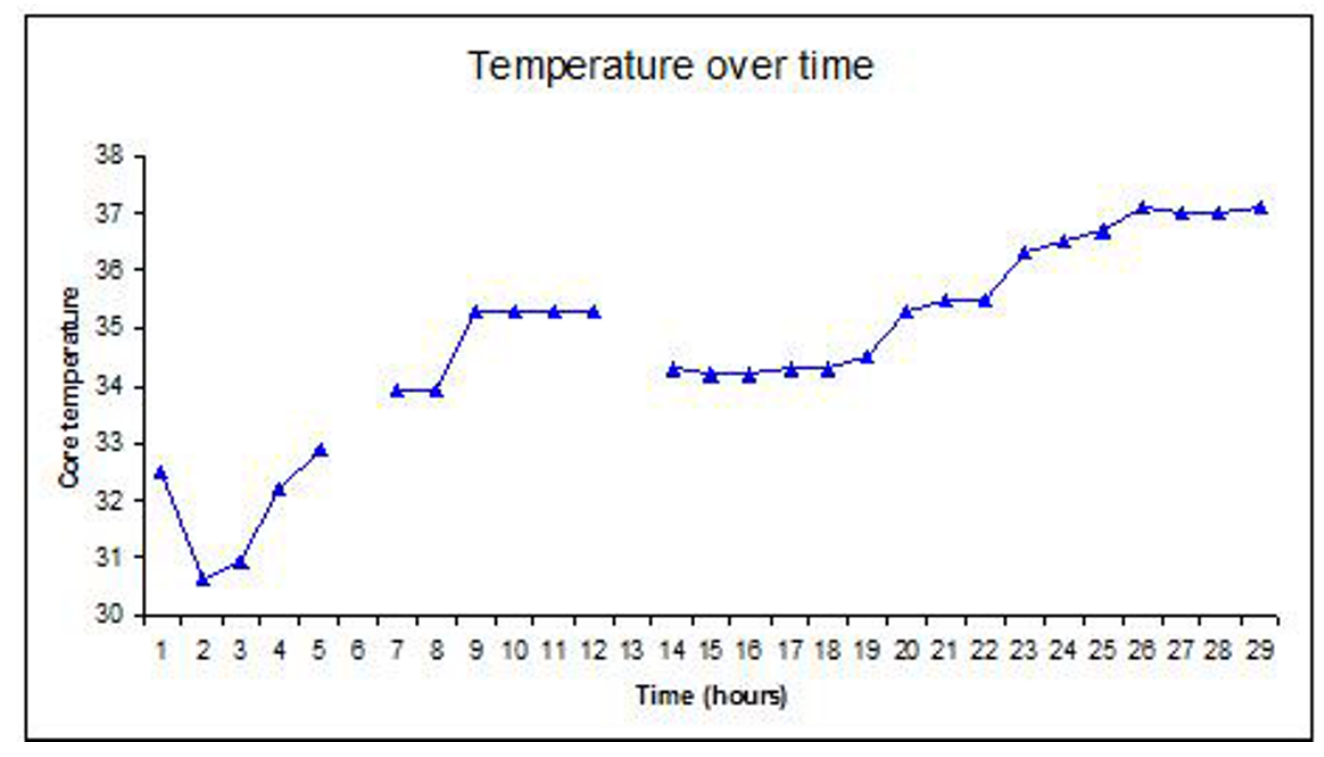

Figure I

Core temperature $\left({ }^{\circ} \mathrm{C}\right)$ over time. 


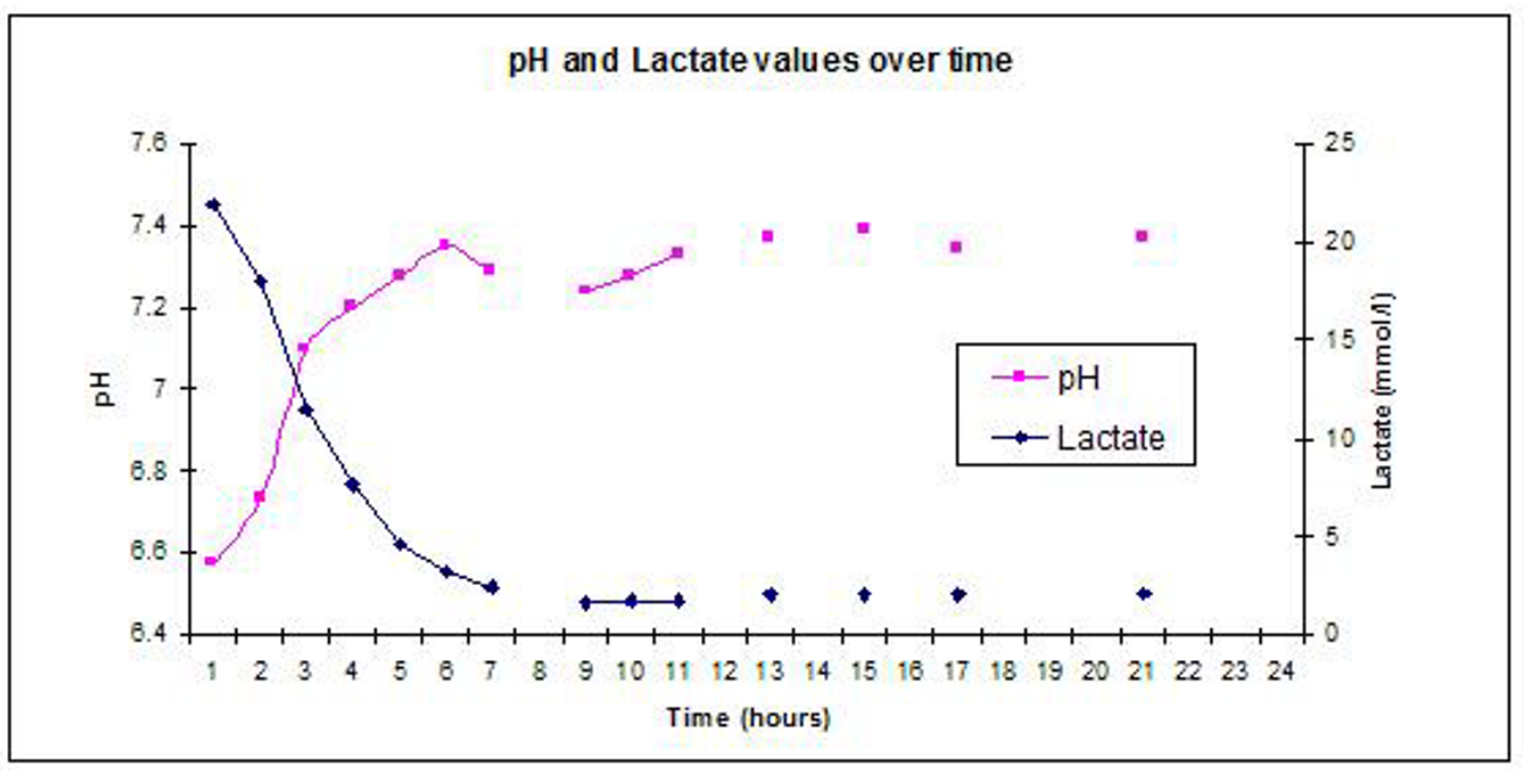

Figure 2

Normalisation of arterial pH and Lactate over time.

clinical studies and concluded that neuroprotective benefit of post ischemic hypothermia directly relates to attenuation of the detrimental processes involved in both necrotic and apoptotic cell death. But there was conflicting evidence surrounding the depth and duration of hypothermia.

The International Liaison Committee for Resuscitation (ILCOR) had suggested that cooling may be beneficial for patients suffering cardiac arrest due to reasons other than ventricular fibrillation [9]. In 2002 the World Congress on Drowning in Amsterdam [10] recommended that victims of drowning who remained unconscious due to hypoxic encephalopathy should be treated with hypothermia of $32-34^{\circ} \mathrm{C}$ for $12-24$ hours along with appropriate seizure control and continuous blood glucose monitoring.

Following ILCOR advisory statement of 2002, American heart association [11] incorporated therapeutic hypothermia in its 2005 recommendations for cardiac arrest patients. It therefore seemed reasonable to apply this intervention in our patient.

The optimum duration and degree of hypothermia remains uncertain and ILCOR recommends a temperature of $32^{\circ} \mathrm{C}$ to $34^{\circ} \mathrm{C}$ for between 12 and 24 hours [9]. There is evidence, at least in traumatic brain injury (5), that more prolonged periods of hypothermia may have greater benefit. A retrospective review of hypothermia for the management of drowning in 40 children[12] found a worse outcome for patients treated with hypothermia compared to normothermic patients when both the duration (24 to 36 hours) and degree of cooling $\left(30^{\circ} \mathrm{C}\right.$ to $33^{\circ} \mathrm{C}$ ) was greater than in our case. The patients in this series were also treated with hyperventilation and highdose barbiturates.

Williamson and colleagues[7] reported a successful outcome in a victim of drowning treated with therapeutic hypothermia. Their case shares many similarities with ours, including profound metabolic acidosis, hyperlactaemia and low GCS with fixed, dilated pupils at presentation. The authors concluded that, in the context of a victim of drowning and in association with hypothermia, these signs may not carry the grave prognosis they would otherwise in critically ill patients. Our findings in this case support this view.

Our experience supports the role of therapeutic hypothermia as part of the management strategy of patients who have suffered hypoxic brain injury as a result of drowning.

\section{Consent}

As is evident from the case report the anonymity of the patient is preserved in every aspect to maintain confidentiality and privacy of the patient.

The report states that the patient stayed in our institution for 4 days only, during which time we had not decided to publish the case report. After repatriation of the patient much effort was taken to get the consent from the patient and her parents, but due to continuous movement of the 
patient from the hospital to the rehabilitation facility it became extremely difficult, the language bar also posed a real challenge towards the consent obtaining procedure

\section{Conflicts of interests}

The authors declare that they have no competing interests.

\section{Authors' contributions}

JJP was the attending intensivist and anaesthetist for the patient. He included therapeutic hypothermia in the plan of management of the patient. RB collected and assimilated the data towards formulation of the case report.

\section{References}

I. Polderman $\mathrm{KH}$ : Induced hypothermia for neuroprotection: understanding the underlying mechanisms. In Yearbook of Intensive Care and Emergency Medicine Springer; 2006.

2. The hypothermia after cardiac arrest study group: Mild therapeutic hypothermia to improve the neurologic outcome after cardiac arrest. New England Journal of Medicine 2002:549-56.

3. Bernard SA, Gray TW, Buist MD, et al.: Treatment of comatose survivors of out-of-hospital cardiac arrest with induced hypothermia. New England Journal of Medicine 2002:557-63.

4. McIntyre LA, Fergusson DA, Hebert PC, et al.: Prolonged therapeutic hypothermia after traumatic brain injury in adults. Journal of the American Medical Association 2003:2992-9.

5. Peterson K, Carson S, Carney N: Hypothermia treatment for traumatic brain injury: a systematic review and meta-analysis. Journal of Neurotrauma 2008:62-7I.

6. Jaramillo $\mathrm{A}$, Illanes $\mathrm{S}$, Diaz V: Is hypothermia useful in malignant ischemic stroke? Current status and future perspectives. Journal of the Neurological Sciences 2008, 266(I-2): I-8.

7. Williamson JP, Illing R, Gertier P, Braude S: Near-drowning treated with therapeutic hypothermia. Medical Journal of Australia 2004, I 8 I(9):500-I.

8. Schaller B, Graf R: Hypothermia and stroke: the pathophysiological background. Pathophysiology 2003:7-35.

9. Nolan JP, Morley PT, Hoek TL, Hickey RW: Advancement Life Support Task Force of the International Liaison Committee on Resuscitation. Therapeutic hypothermia after cardiac arrest: An advisory statement by the Advanced Life Support Task Force of the international Liaison Committee on Resuscitation. Resuscitation 2003:23I-235.

10. Bierens J], Knape JT, Gelissen HP: Drowning. Current Opinions in Critical Care 2002:578-86.

11. American Heart Association: [http://www.americanheart.org].

12. Bohn DJ, Biggar WD, Smith CR, et al.: Influence of hypothermia, barbiturate therapy and intracranial pressure monitoring on morbidity and mortality after near drowning. Critical Care Medicine 1986:529-534.
Publish with Bio Med Central and every scientist can read your work free of charge

"BioMed Central will be the most significant development for disseminating the results of biomedical research in our lifetime. "

Sir Paul Nurse, Cancer Research UK

Your research papers will be:

- available free of charge to the entire biomedical community

- peer reviewed and published immediately upon acceptance

- cited in PubMed and archived on PubMed Central

- yours - you keep the copyright
BioMedcentral 